\title{
Potential Use of Essentials Oils to Control Fruitlet Core Rot (FCR) in Pineapple (Queen Victoria Variety) in Reunion Island
}

\author{
Marc Chillet ${ }^{1,2}$, Angélique Hoareau ${ }^{1,2}$, Mathilde Hoarau ${ }^{1,2}$, Jérome Minier ${ }^{1,2}$ \\ ${ }^{1}$ CIRAD, UMR QUALISUD, 7 Chemin de l'IRAT, 97410 Saint Pierre, Ile de la Réunion, France \\ ${ }^{2}$ QUALISUD, Univ. Montpellier, CIRAD, Montpellier SupAgro, Univ. d'Avignon, Univ. de la Réunion, Montpellier, France \\ Email: marc.chillet@cirad.fr
}

How to cite this paper: Chillet, M., Hoareau, A., Hoarau, M. and Minier, J. (2020) Potential Use of Essentials Oils to Control Fruitlet Core Rot (FCR) in Pineapple (Queen Victoria Variety) in Reunion Island. American Journal of Plant Sciences, 11, 1671-1681.

https://doi.org/10.4236/ajps.2020.1111119

Received: September 27, 2020

Accepted: November 10, 2020

Published: November 13, 2020

Copyright $\odot 2020$ by author(s) and Scientific Research Publishing Inc. This work is licensed under the Creative Commons Attribution International License (CC BY 4.0).

http://creativecommons.org/licenses/by/4.0/

\begin{abstract}
Fruitlet Core Rot (FCR) is one of the major postharvest diseases of pineapple (Ananas comosus var. comosus), especially on the prone variety Queen Victoria cultivated in Reunion Island. This aggressive disease is generally due to two pathogens: Fusarium ananatum and Thalaromyces stolii, and needs to be controlled during postharvest. In Reunion Island, $F$. ananatum is the principal causal agent impacting fruit exportation. Fruit produced for the export market is generally treated with chemicals. This type of postharvest treatment is not in line with consumer expectations, as consumers prefer fruits treated with nonharmful and natural products. The objective of this work was to study alternative postharvest treatments using the fungitoxic properties of essential oils and their ability to elicit the resistance mechanisms of the fruit. Six EAs were tested in vitro on mycelial growth of $F$. ananatum. Whether by volatilization or included in the culture medium, some essential oils such as thymol, eugenol, geraniol and the carvone/menthol mixture have a strong fungistatic effect. But only thymol has a fungitoxic effect. The thymol, a natural molecule synthesized by thyme (Thymus vulgaris L. thymoliferum) is the more effective in vitro and is the strongest potential to be used in postharvest treatment. Thymol, prepared at $0.025 \%$ in a terpene solvent that acts as a penetrating agent, was tested in vivo with inoculated fruits. The treatment was effective only on necrosis development from the upper part of the fruits. Pineapple polyphenol biosynthesis appears to have been suppressed by thymol treatment. Results and opportunities for this treatment are discussed. Additional experiments must be carried out in order to decide on the advisability of this type of treatment.
\end{abstract}

\section{Keywords}

Essential Oils, Fruitlet Core Rot, Pineapple, Postharvest Treatment, Thymol 


\section{Introduction}

Pineapple (Ananas comosus L.) is one of the ten most cultivated fruits in the world. It is also grown in French outermost regions, especially on the Carib islands (Guadeloupe and Martinique) and particularly in the Indian Ocean, on Reunion Island, where it is the most important fruit crop. Pineapple (Ananas comosus $\mathrm{L}$.) is a tropical and subtropical non-climacteric fruit that is well known for its high nutritional value [1].

Moreover, this fruit is susceptible to a number of fungal diseases, of which FCR caused by $F$. ananatum is the most severe [2]. The pathogen penetrates the plant during the flowering stage through stylar canals and nectary ducts [3]. Once the fungus reaches the floral cavity, it remains latent during fruit growth [4]. There are physiological changes following the pathogen attack, and the phenylpropanoid pathway is solicited on pineapple [5] [6]. This author showed an accumulation of free coumaroylisocitrate and caffeoylisocitrate in pineapple fruitlets following infection with $F$. ananatum. These hydroxycinnamic acids (HCA) play an important role in plant-pathogen interactions with their antifungal properties and have an implication in lignin biosynthesis.

To limit disease development during storage, pineapple is usually treated with a chemical fungicide like prochloraz [7]. However, the application of synthetic fungicides to control postharvest diseases is regulated in several countries, due to their effects on environmental pollution and possible effects on human being's health [8]. The increasing emergence of fungicide-resistant isolates of pathogens and problems related to fungicide toxicity, new alternatives methods for controlling this type of disease have been proposed, including the use of vegetal extracts properties [9].

Natural antifungal compounds such as essential oils have properties to be an alternative solution for the control of postharvest diseases [9] [10] [11]. Essential oils can have antimicrobials properties and can stimulate the physiological mechanism of resistance of the fruits [12] [13] [14] [15].

The main objective of our study was to test alternative postharvest treatment methods against FCR. In this study, we tested the fungitoxic effect of several essential oils against $F$. ananatum in vitro and in vivo, and the effect of these treatments on fruit physiology and quality.

\section{Materials and Methods}

\subsection{Plant Material}

The FCR-prone pineapple (Ananas comosus) var. Queen Victoria was cultivated at the experimental station of CIRAD, in Saint Pierre, Reunion Island $\left(21^{\circ} 6^{\prime} \mathrm{S}\right.$ $55^{\circ} 32^{\prime} \mathrm{E}$, tropical climate, average annual temperature $=25^{\circ} \mathrm{C}$, rainfall $=1000$ $\mathrm{mm}$ /year, ferrallitic soils). Fruits were harvested at a commercial maturity stage for exportation.

\subsection{Pathogen}

The Clp001 Fusarium ananatum strain used for the inoculations was taken from 
the CIRAD collection of fungal pathogens. The fungus was isolated from naturally infected "Queen" pineapple on Réunion Island and purified in selective media. The Fusarium-specific primer elongation factor tef- $1 \alpha$ and tef- $2 \alpha$ made it possible to identify Clp001 as a Fusarium ananatum [6].

\subsection{In Vitro Test}

Six essentials oils were tested on mycelium growth (Carvone/Menthol from Mentha canadensis, Eugenol from Syzygium aromaticum; Geraniol from Geranium sp:; Lavandula angustifolial Eucalyptus globulus; Thymol from Thymus vulgaris). We tested the effect of the oils by volatilization and by contact (oil included in the culture media). These EOs have already been tested on other fruit pathologies and present real potential in post-harvest treatment (cost and efficacy).

To test the effect of each essential oil on C. gloeosporioides in vitro, 1, 2, 5 and $10 \mu \mathrm{L}$ of each oil were deposited on the lid of a Petri dish (oil volatilization), and $(0.15 \%, 0.10 \%, 0.05 \%, 0.025 \%, 0.01 \%)$ included in the PDA (oil contact). For each experiment, ten Petri dishes were treated and ten were used as controls. After one week of incubation at $25^{\circ} \mathrm{C}$ (fungistatic activity), the inoculum was placed in another Petri dish without essential oil to test the fungitoxic effect (7 days). The mycelial growth inhibition (MGI) represents the percentage of inhibitory effect of the treatment. It is calculated by the formula:

$$
\text { MGI }=100-\left(\frac{\text { Diameter treated }}{\text { Diameter control }}\right)
$$

The experiment was repeated three times. To search for the MIC, we repeated this experiment with 2 and $1 \mu \mathrm{L}$ of Thymol oil.

\subsection{In Vivo Tests-Fruit Inoculation}

Treatment solutions were prepared with crystals of pure thymol (number CAS 89-83-8) from Xeda International SA (Saint Andiol, France) diluted in terpene preparations made with the commercial product Heliosol ${ }^{\circledR}(665 \mathrm{~g} / \mathrm{L}$ terpenic alcohol) prepared at $2 \mathrm{~mL} / \mathrm{L}$, referred to as CS in this paper for the in vivo tests.

The Clp001 Fusarium ananatum strain was cultivated in Petri dishes for 15 days on PDA solid medium at $27.5^{\circ} \mathrm{C}$ in the dark. A fungal suspension was made in sterile water and adjusted to $10^{3}$ conidia $\mathrm{mL}^{-1}$. Fruits were immediately inoculated after this step. Twenty-five microliters of the conidial suspension were injected into the parenchyma adjacent to the remnant floral cavity. Four fruitlets were inoculated per fruit. Two inoculation points are located on the upper part of the fruit, and two points are located on the lower part. To ensure that the FCR was due to CLP001, the pulps from non-inoculated and inoculated fruits were placed on PDA amended with chloramphenicol and left for $8 \mathrm{~d}$ at $25^{\circ} \mathrm{C}$. The identification of the re-isolated fungi was based on morphological criteria. After inoculation, fruits were maintained at room temperature for $24 \mathrm{~h}\left(21^{\circ} \mathrm{C}, 85 \%\right.$ relative humidity). 
Inoculated fruits were then dipped in 1) water as a control, 2) the terpene solvent ( $\mathrm{HE})$ as a second control, and 3) thymol/terpene solvent and allowed to air dry at room temperature. The soaking time was 2 minutes.

In this experiment, we compared the effect of two different concentrations of thymol in the solvent (Heliosol) $(0.025 \%$ of thymol: T0.025; $0.01 \%$ of thymol: T0.01) with two control (T0: water, HE: Heliosol). The experiment was repeated two times ( 48 fruits for each replicate of the experiment-12 fruits per modality (T0.025, T0.01, HE, T0)). The objective was to determine the most effective concentration on disease development that did not affect fruit quality.

Inoculated and treated fruits were packed in sealed plastic boxes $(30 \mathrm{~L})$ and maintained at $20^{\circ} \mathrm{C}$ for 7 days. Observations of FCR (lesion surface in $\mathrm{mm}^{2}$ ) were recorded at the end of the storage time (7 days). For FCR, we measured the length (L) and width (w) of the developed necrosis of the inoculation area of each fruit and calculated the surface of each necrosis by the formula of the area of an ellipse: $\mathrm{L} \times \mathrm{w} \times \pi / 4$.

\subsection{Biochemical Analyses}

After 7 days of storage at $20^{\circ} \mathrm{C}$, the fruits (from T0 and T0.025/necrotic zone and healthy zone) were analysed. All fruits were weighed before and after storage to measure weight loss with a precision balance Sartorius CP3202S (Sartorius Lab Instruments $\mathrm{GmbH} \&$ Co. Goettingen, Germany. Peel and pulp were separated and frozen at $-80^{\circ} \mathrm{C}$. Polyphenols compounds were analysed using high-performance liquid chromatography (HPLC) on fruit peels. HPLC analysis was performed using a Dionex Ultimate 300 apparatus (Dionex Co., Sunnyvale, CA, USA) equipped with a diode array detector. The column used was a reverse-phase Waters Symmetry Shield C18, $250 \times 4.6 \mathrm{~mm}, 5 \mu \mathrm{m}$.

\subsection{Statistical Analysis}

The methodology used to treat data was the randomized block design approach. The experiments were repeated in triplicate, and the data were analysed with the general linear model (GLM) procedure in the Excel Stat computer programme. Mean values were separated by LSD values (5\%) using the least significant difference (LSD) test and homogenous groups were determined using the Newman-Keuls test.

\section{Results}

\subsection{Effect of Essential Oils on F, ananatum in Vitro}

- Essential oil by volatilization

The essential oil with the strongest inhibitory effect at the lowest concentrations is Thymol (Figure 1). In amounts between 5 and $2 \mu \mathrm{L}$, it inhibits mycelial growth $100 \%$. In addition, this inhibitory effect remains very high after transplanting the mycelium onto a nutrient medium without essential oils, while the other treatments did not have this second effect (Figure 2). This experience 


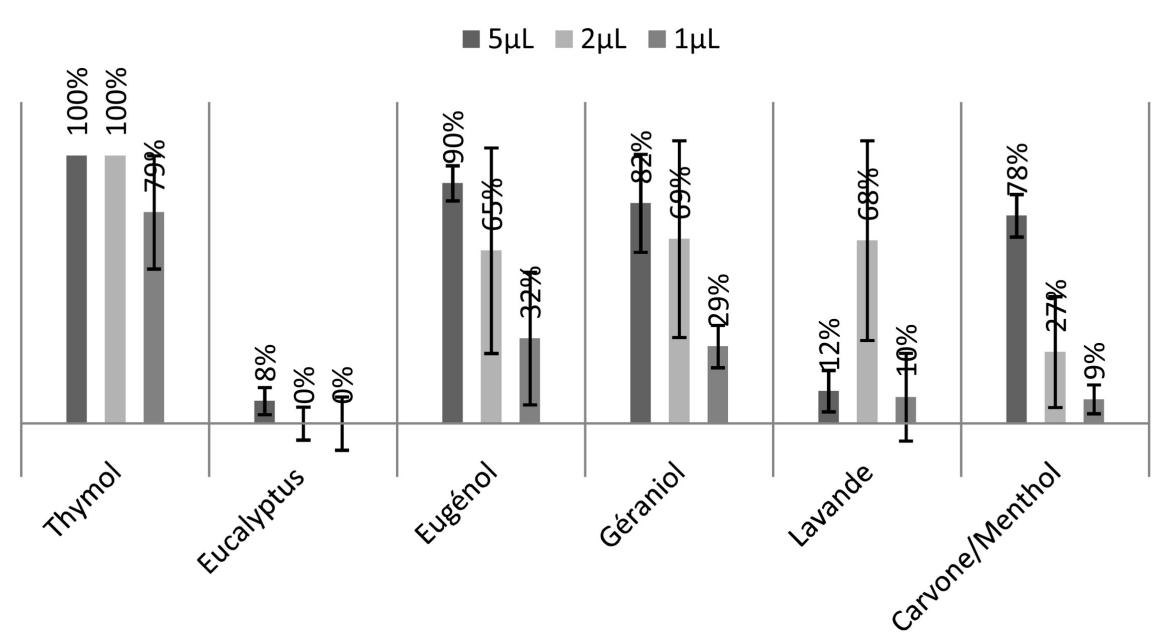

Figure 1. Percentage inhibition of mycelial growth in vitro after 8 days of treatment with volatilization of essential oils.

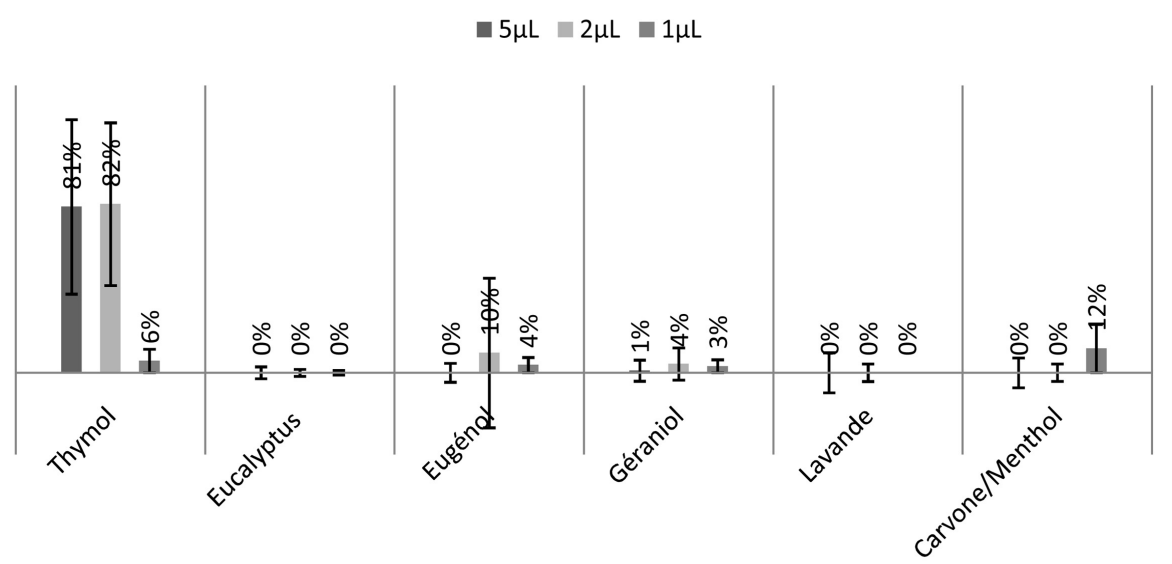

Figure 2. Percentage inhibition of mycelial growth when plots are deposited on PDA (after treatment by volatilisaztion).

therefore shows the fungistatic but also fungitoxic effect of Thymol.

- PDA media with incorporation of essential oil

Measuring the growth of mycelia on a medium supplemented with essential oils shows that Thymol is $100 \%$ effective for all the concentrations tested (Figure 3). Likewise, it has a lasting inhibitory effect after transplanting, for concentrations ranging from $0.15 \%$ to $0.05 \%$ (Figure 4 ).

The thymol-based treatment is the most effective of all the molecules tested, whether by volatilization or included in the PDA culture medium. This is the thymol treatment that will be used for in vivo experiments.

\subsection{Effect of Essential Oil on Necrosis Development in Vivo}

On the inoculations located on the upper part of the fruit, there is a very clear significant effect of the Heliosol/Thymol treatment on the development of necrosis. Treatments TH0.025 and T0.01 had smaller areas of necrosis than the two controls (Figure 5). 


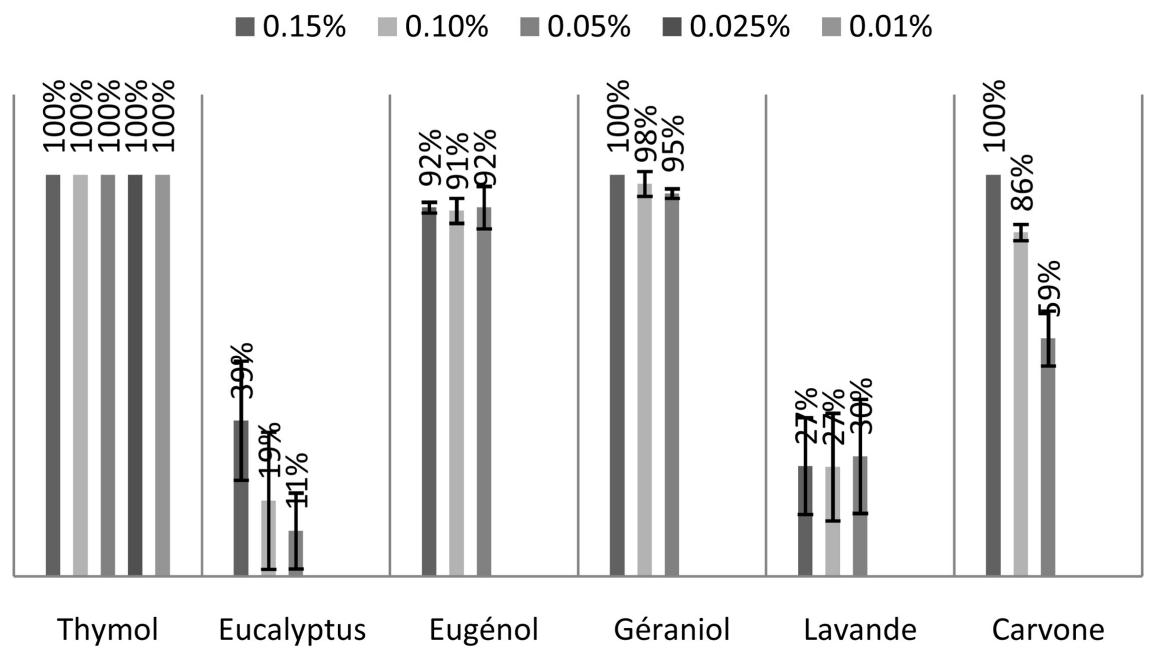

Figure 3. Percentage inhibition of mycelial growth on PDA with essentials oils.

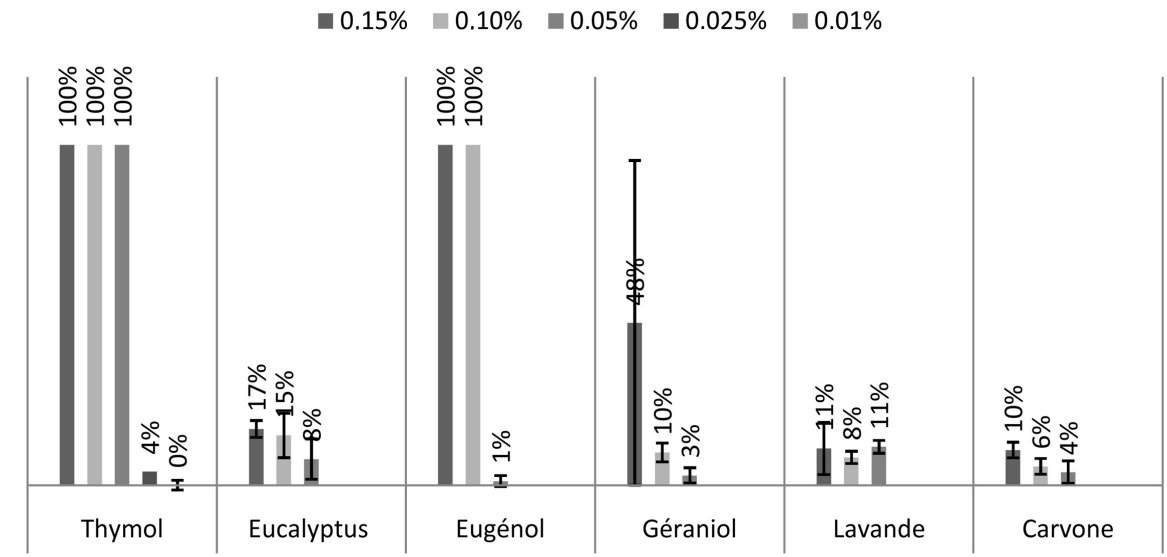

Figure 4. Percentage inhibition of mycelial growth when plots are deposited on PDA (after treatment by essential oil incorporated in the media culture).

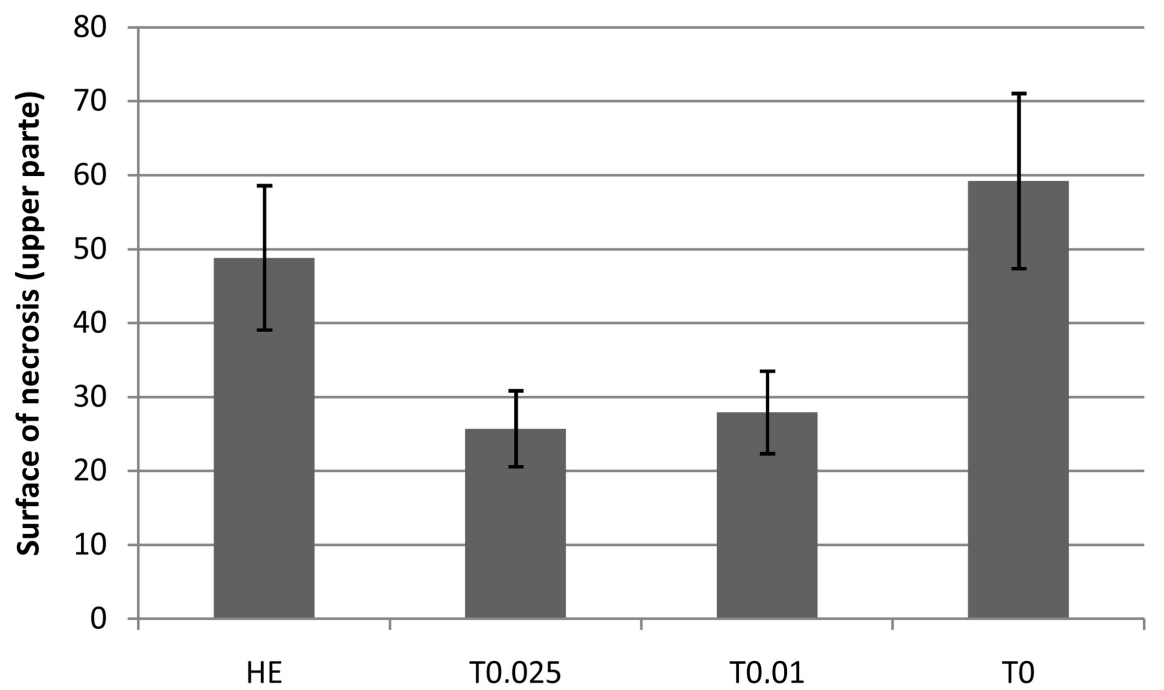

Figure 5. Surface of necrosis 7 days after inoculation by $F$. ananatum in the upper part of the pineapple. Fruits were stored in climatic room at $20^{\circ} \mathrm{C}$. 
However, the results are different for the lower part of the fruit; necrosis in this area developed in the same way and treatment with Thymol had no effect (Figure 6).

\subsection{Polyphenol Content}

The polyphenols were extracted from the fruit pulp and the contents were measured by HPLC. They have been classified into two main categories of polyphenols, HBA and HCA. The HCAs are those which are directly involved in the mechanisms of resistance of the fruit to FCR.

Figure 7 shows the HBA levels in the inoculated and uninoculated zones of thymol-treated or untreated fruit. It is found that the thymol/Heliosol treatment

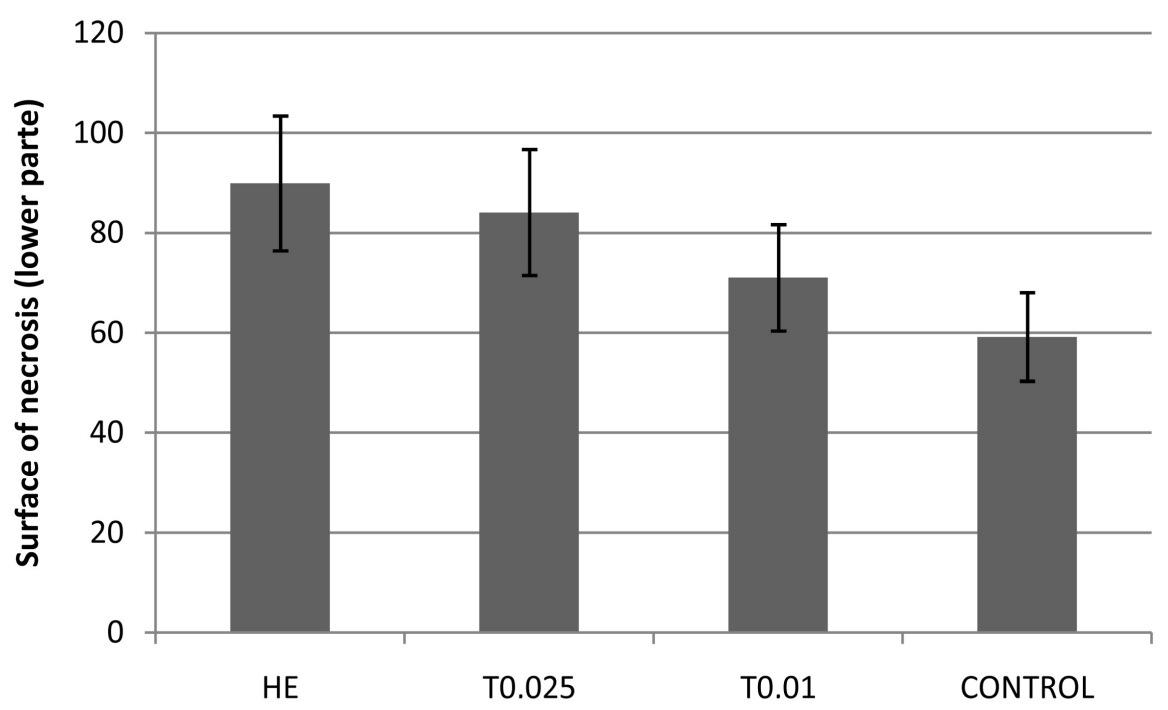

Figure 6. Surface of necrosis 7 days after inoculation by $F$. ananatum in the lower part of pineapple. Fruits were stored in climatic room at $20^{\circ} \mathrm{C}$.

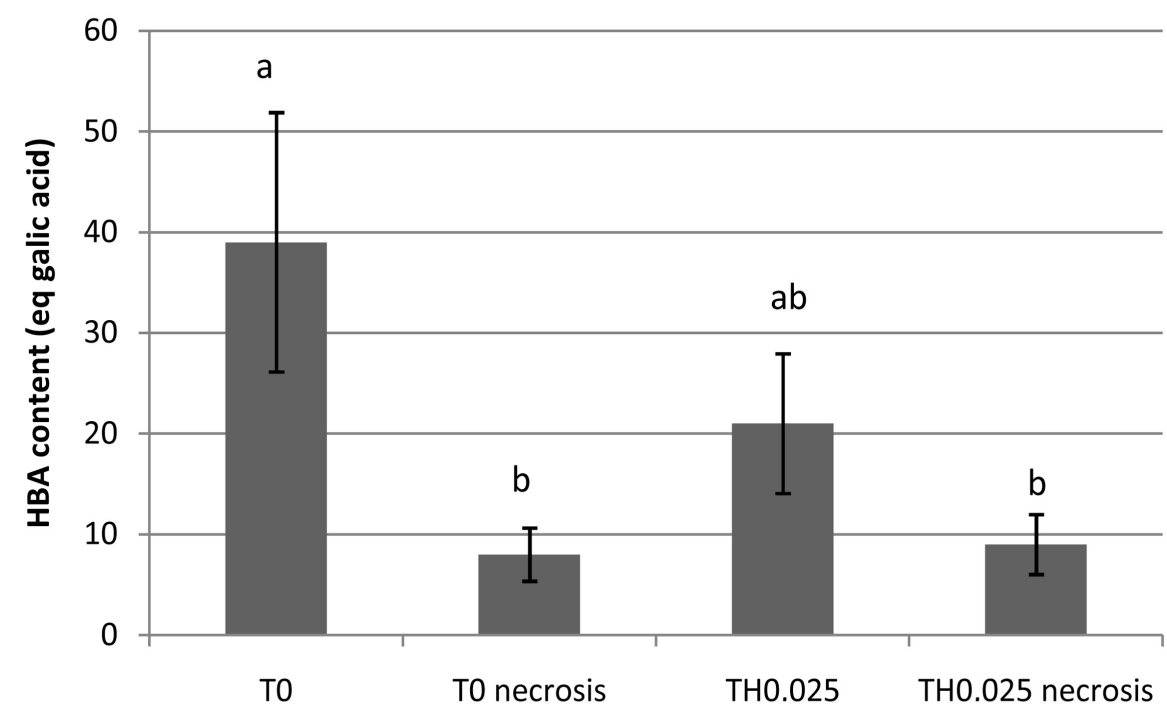

Figure 7. Hydroxybenzoic acids content in pineapples: T0 = Control (healthy and necrotic area) and treated with $0.025 \%$ Thymol/Heliosol (healthy and necrotic area). 
has an effect on the synthesis of HBAs. The contents in the healthy zones of the treated fruits are lower and significantly different than in the control fruits. The quantities are equivalent in the necrotic zones.

Figure 8 shows the HCA levels in the inoculated and uninoculated zones of thymol-treated or untreated fruit. The effect of the treatment is very significant; it leads to a decrease in HCA contents in necrotic areas as in healthy zones.

\section{Discussion}

Experiments carried out in vitro have shown that Eos had an inhibitory effect on mycelial growth of $F$. ananatum. Eugenol and Thymol are the two molecules most effective on fungus growth in vitro. In contrast, some Eos such as eucalyptus has almost no effect on the fungus.

Thymol, incorporated into the culture medium or in volatilization, is the most efficient molecule on $F$. ananatum growth. Thymol is not just fungistatic like Geraniol and Eugenol, but it is also fungitoxic.

This result is entirely consistent with previous studies on pathogens from mangoes [12], avocado [16], banana [17] and even pineapple with pathogen $F$. verticilloides [11]; thymol is the most fungitoxic molecule in vitro for many fruit pathogens.

The in vivo experiments gave somewhat more contrasting results. Thymol had no effect on the lower part of fruits inoculated with $F$. ananatum (necrosis developed in the same way regardless of the treatment), whereas the effect was significant for the two treatments with different doses of thymol $(0.01 \%$ and $0.025 \%)$ in the upper part. Fruit ripens from below [18]; the lower zone is, therefore, more advanced in ripening (it is yellower and sweeter than the upper part) at the time of inoculation. There is a biochemical gradient into the fruit concerning several chemical parameters like total soluble solids (TSS), vitamin C

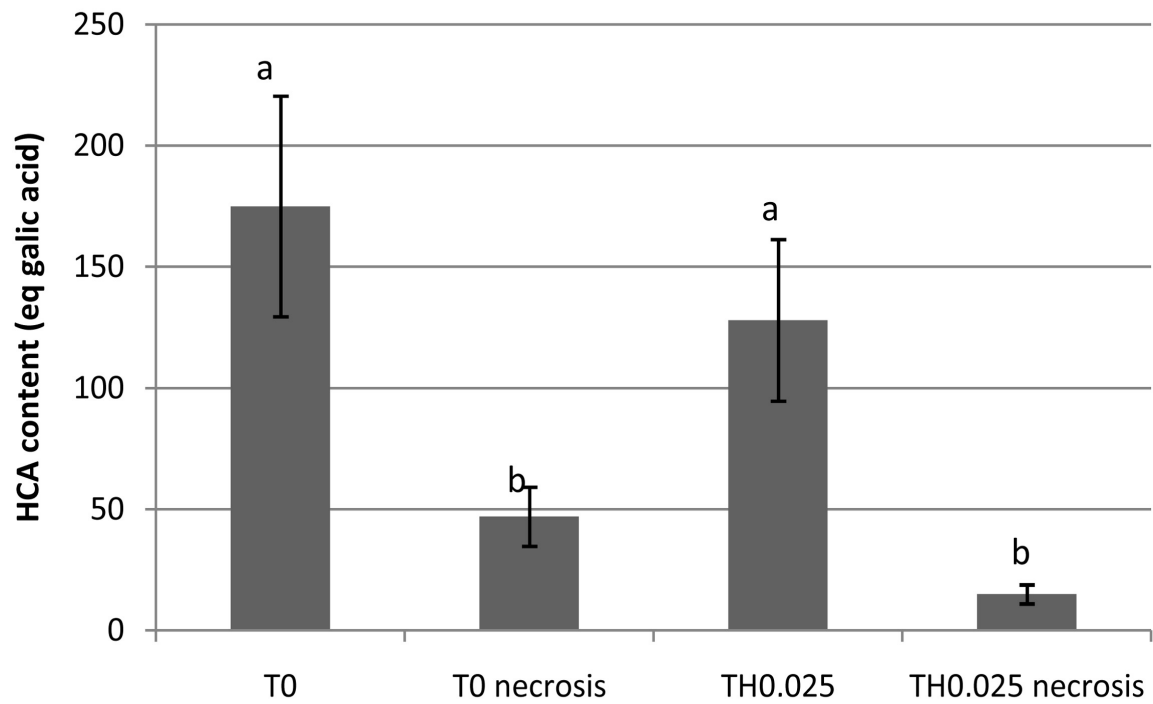

Figure 8. Hydroxycinamic acids content in pineapples: T0 = Control (healthy and necrotic area) and treated with $0.025 \%$ Thymol/Heliosol (healthy and necrotic area). 
(ascorbic acid), titratable acidity (TA), and pulp pH [19] [20]. Pathogen's spores were therefore able to germinate rapidly during the latency period between inoculation and treatment $(24 \mathrm{~h})$. By the time of treatment, the mycelia of the fungus had probably already penetrated the pineapple flesh and could no longer be reached by the thymol treatment.

In the upper part of fruit, at inoculation time, the fruit is still green, acid and not very sweet. The inoculated spores may not germinate immediately, as in the lower part of the fruit. These are then more easily reached by thymol treatment. This, therefore, causes smaller necrosis on the upper parts of fruits treated with thymol.

From a biochemical point of view, our results concerning the contents of HBA and HCA show that thymol treatments $(0.01 \%$ and $0.025 \%)$ inhibited polyphenols synthesis in healthy areas as in necrotic areas. This result is contrary to what was obtained on mangoes [13] [14] and avocado [15] where the synthesis of polyphenolic compounds involved in the resistance mechanisms of fruits was elicited. The HBA contents generally remain stable or decrease lightly when necrosis develops, and the HCA contents increase strongly [6]. Thymol treatment disrupted the polyphenol biosynthesis chain characterized by a drop in levels.

Additional experiments must be carried out in order to determine the interest of this type of treatment on the FCR, and to measure the effects on the quality of the fruits.

\section{Conclusion}

The essential oils tested are, apart from eucalyptus oil, very fungistatic, and even fungitoxic for Eugenol and especially Thymol. This molecule is strongly active against the growth of the pathogen Fusarium ananatum in vitro. However, the treatment of fruits inoculated with a thymol/heliosol mixture is only effective on necrosis development in the upper part of the fruit, an area still immature at the inoculation time. Finally, thymol treatment does not seem to elicit the resistance mechanisms of the fruit.

\section{Conflicts of Interest}

The authors declare no conflicts of interest regarding the publication of this paper.

\section{References}

[1] Liu, J., He, C., Shen, F., Zhang, K. and Zhu, S. (2017) The Crown Plays an Important Role in Maintaining Quality of Harvested Pineapple. In: Nicolai, B. and Watkins, C., Eds., Postharvest Biology and Technology, Elsevier, Amsterdam, 18-24. https://doi.org/10.1016/j.postharvbio.2016.09.007

[2] Barral, B., Filippi, L., Chillet, M., Léchaudel, M. and Schorr-Galindo, S. (2017) Diagnostic Survey on the Occurrence of Pineapple Fruitlet Core Rot and Relationship with Phenolic Compounds in Réunion Island. International Symposium of Postharvest Pathology, Skukuza (South Africa), 28 May-2 June 2017. 
[3] Rohrbach, K.G. and Pfeiffer, J.B. (1976) Susceptibility of Pineapple Cultivars to Fruit Diseases Incited by Penicillium-Funiculosum and Fusarium-Moniliforme. Phytopathology, 66, 1386-1390. https://doi.org/10.1094/Phyto-66-1386

[4] Mourichon, X. (1983) Contribution à l'etude des taches noires (Fruitlet core rot) et leathery pocket de l'ananas causés par Penicillium funiculosum Thom. en Côte d'Ivoire. Fruits, 38, 601-609.

[5] Barral, B., Chillet, M., Minier, J., Léchaudel, M. and Schorr-Galindo, S. (2017) Evaluating the Response to Fusarium ananatum Inoculation and Antifungal Activity of Phenolic Acids in Pineapple. Fungal Biology, 121, 1045-1053.

https://doi.org/10.1016/j.funbio.2017.09.002

[6] Barral, B., Chillet, M., Léchaudel, M., Lartaud, M., Verdeil, J.L., Conéjéro, G. and Schorr-Galindo, S. (2019) An Imaging Approach to Identify Mechanisms of Resistance to Pineapple Fruitlet Core Rot. Frontiers in Plant Science, 10, 1-12. https://doi.org/10.3389/fpls.2019.01065

[7] Abdullah, H. (2011) Quality Maintenance of Pineapple in Postharvest Handling. Acta Horticulturae, 902, 403-408. https://doi.org/10.17660/ActaHortic.2011.902.48

[8] Feng, W. and Zheng, X. (2007) Essential Oils to Control Alternariaalternata in Vitro and in Vivo. In: Campbell-Platt, G., Ed., Food Control, Elsevier, Amsterdam, 1126-1130. https://doi.org/10.1016/j.foodcont.2006.05.017

[9] Sellamuthu, P.S., Sivakumar, D., Soundy, P. and Korsten, L. (2013) Essential Oil Vapours Suppress the Development of Anthracnose and Enhance Defense Related and Antioxidant Enzyme Activities in Avocado Fruit. Postharvest Biology and Technology, 81, 66-72. https://doi.org/10.1016/j.postharvbio.2013.02.007

[10] Farzaneh, M., Kiani, H., Sharifi, R., Reisi, M. and Hadian, J. (2015) Chemical Composite on and Antifungal Effects of Three Species of Satureja (S. hortensis, S. spicigera, and $S$. khuzistanica) Essential Oils on the Main Pathogens of Strawberry Fruit. Postharvest Biology and Technology, 109, 145-151. https://doi.org/10.1016/j.postharvbio.2015.06.014

[11] Vilaplana, R., Pérez-Revelo, K. and Valencia-Chamorro, S. (2018) Essential Oils as an Alternative Postharvest Treatment to Control Fusariosis, Caused by Fusarium verticillioides, in Fresh Pineapples (Ananas comosus). Scientia Horticulturae, 238, 255-263. https://doi.org/10.1016/j.scienta.2018.04.052

[12] Chillet, M., Minier, J., Ducrocq, M. and Meile, J.C. (2018) Postharvest Treatment of Mango: Potential Use of Essential Oil with Thymol to Control Anthracnose Development. Fruits, 73, 153-157. https://doi.org/10.17660/th2018/73.3.2

[13] Chillet, M., Minier, J., Hoarau, M. and Meile, J.C. (2019) Potential Use of Thymol to Control Anthracnose Development in Mango. European Journal of Plant Pathology, 155, 943-952. https://doi.org/10.1007/s10658-019-01825-9

[14] Chillet, M., Minier, J., Hoarau, M. and Meile, J.C. (2020) Optimisation of the Postharvest Treatment with Thymol to Control Mango Anthracnose. American Journal of Plant Sciences, 11, 1235-1246. https://doi.org/10.4236/ajps.2020.118087

[15] Bill, M., Sivakumar, D., Beukes, M. and Kortsen, L. (2016) Expression of Pathogenesis-Related (PR) Genes in Avocados Fumigated with Thyme Oil Vapour and Control of Anthracnose. Food Chemistry, 194, 938-939. https://doi.org/10.1016/j.foodchem.2015.08.105

[16] Bill, M., Sivakumar, D., Korsten, L. and Thompson, A.K. (2014) The Efficacy of Combined Application of Edible Coatings and Thyme Oil in Inducing Resistance Components in Avocado (Persea americana Mill.) against Anthracnose during Post-Harvest storage. Crop Protection, 64, 158-167. 
https://doi.org/10.1016/j.cropro.2014.06.015

[17] Vilaplana, R., Pazmiño, L. and Valencia-Chamorro, S. (2018) Control of Anthracnose, Caused by Colletotrichum musae, on Postharvest Organic Banana by Thyme Oil. Postharvest Biology and Technology, 138, 56-63.

https://doi.org/10.1016/j.postharvbio.2017.12.008

[18] Dou, M.A., Yao, Y.L., Du, L.Q., Sun, G.M., Zhang, X.M. and Li, J.G. (2010) Sugar Accumulation Difference between the Various Sections during Pineapple Development. VII International Pineapple Symposium, Johor Bahru, Malaysia, 31 July 2011, 141-149. https://doi.org/10.17660/ActaHortic.2011.902.12

[19] Reinhardt, D.H., Medina, V.M., Caldas, R.C., Pinto da Cunha, G.A. and Herrera Estevam, R.F. (2004) Gradientes de qualidade em abacaxi 'pérola' em função do tamanho e do estádio de maturação do fruto1. Revista Brasileira de Fruticultura, 26, 544-546. https://doi.org/10.1590/S0100-29452004000300041

[20] Ramallo, L.A. and Mascheroni, R.H. (2004) Prediction and Determination of Ascorbic Acid Content during Pineapple Drying. Proceedings of the 14th International Drying Symposium (IDS 2004), São Paulo, Brazil, 22-25 August 2004, 1984-1991. 